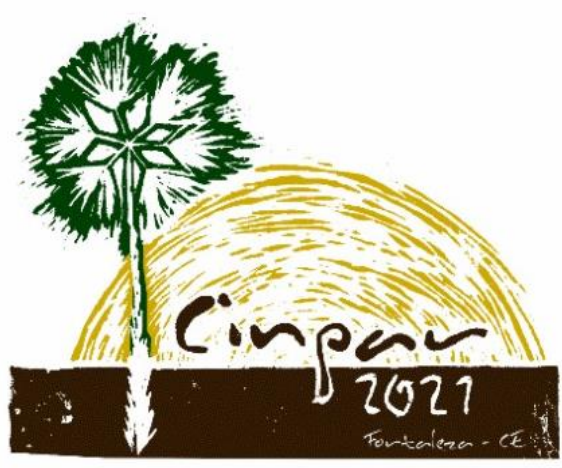

XVII Congresso Internacional sobre Patologia e Reabilitação das Construções

XVII Congreso Internacional sobre Patología y Rehabilitación de las Construcciones

XVII International Conference on Pathology and Constructions Rehabilitation

FORTALEZA (Brasil), 3 a 5 de junho de 2021

https://doi.org/10.4322/CINPAR.2021.166

\title{
Estudo experimental da evolução da resistência à compressão axial do concreto em função da idade
}

\section{Experimental study of the evolution of axial compression strength of concrete due to age}

\author{
Ana Paula Pais GOTT ${ }^{1}$, Gabriela Santos DE ANDRADE², Laura Kaddyjean Oliveira SOARES ${ }^{3}$, Thiago Pena \\ BORTONE ${ }^{4}$, Rachel Jardim MARTINI ${ }^{5}$, Marcos de Paulo RAMOS ${ }^{6}$ \\ ${ }^{1}$ CEFET-MG, Curvelo, Brasil, anapaulapaisgott@hotmail.com \\ ${ }^{2}$ CEFET-MG, Curvelo, Brasil, gabrielaandrade74@hotmail.com \\ ${ }^{3}$ CEFET-MG, Curvelo, Brasil, laurakaddyjean@ymail.com \\ ${ }^{4}$ CEFET-MG, Curvelo, Brasil, thiago.bortone@cefetmg.br \\ ${ }^{5}$ CEFET-MG, Curvelo, Brasil, martini@cefetmg.br \\ ${ }^{6}$ CEFET-MG, Curvelo, Brasil, marcos.ramos@cefetmg.br
}

Resumo: O concreto é o segundo material mais utilizado no mundo e é resultado da mistura de materiais aglomerantes, agregados fragmentados e água. Quando empregado na Construção Civil, confere aos elementos a capacidade de resistir a tensões sem se romper. Essa capacidade é a propriedade mais importante quando se trata do controle e qualidade do concreto, viabilizando a durabilidade das edificações. A capacidade de resistir às tensões é verificada através do ensaio de compressão axial de corpos de prova e os resultados obtidos são avaliados de acordo com o tempo decorrido desde a moldagem até o dia da execução do ensaio, sendo que a resistência requerida em projeto deve ser atendida na idade de 28 dias.

A resistência à compressão axial e outras propriedades mecânicas do concreto são influenciadas por diversos fatores, tais como: as características e proporção dos materiais constituintes da mistura, índice de porosidade e teor de umidade.

O presente trabalho tem como objetivo avaliar a evolução da resistência à compressão axial do concreto em função da sua idade, confrontando os valores de referência previstos na norma vigente de cálculo de estruturas de concreto. Os materiais utilizados foram coletados na Região Central do Estado de Minas Gerais e disponibilizados por uma usina de concreto localizada na cidade de Curvelo-MG. Os resultados obtidos demonstram, para esse estudo, um viés normativo não conservador na definição da resistência à compressão axial do concreto em idades inferiores a 28 dias.

Palavras-chave: Concreto, Resistência à compressão, Evolução das propriedades do concreto.

Abstract: Concrete is the second most used material in the world and is the result of the mixture of binder materials, fragmented aggregates, and water. When used in civil construction, it gives the elements the ability to resist stresses without breaking. This capacity is the most important property when it comes to concrete control and quality, enabling the durability of buildings. The ability to resist stresses is verified by testing specimens for axial compression and the results are evaluated according to the time elapsed from molding to the day the test is performed, and the strength required in the project must be met at an age of 28 days. 
The axial compressive strength and other mechanical properties of concrete are influenced by several factors, such as: the characteristics and proportion of the materials in the mixture, porosity index, and moisture content.

The present work aims to evaluate the evolution of the axial compressive strength of concrete as a function of age, comparing the reference values provided in the current standard for the calculation of concrete structures. The materials used were collected in the central region of the state of Minas Gerais made available by a concrete plant located in the city of Curvelo-MG. The results obtained demonstrate, for these studies, a non-conservative normative bias in the definition of the axial compression strength of concrete at ages less than 28 days.

Keywords: Concrete, Compressive strength, Evolution of concrete properties.

\section{Introdução}

O concreto é o resultado da mistura entre materiais aglomerantes, agregados e água e, é o material mais utilizado na Construção Civil. De acordo com Mehta e Monteiro (1994), o concreto é utilizado desde a antiguidade, pelos povos Egípcios, Gregos e Romanos, os quais aplicavam o material em construções destinadas a contenção de água pelo fato do mesmo possuir uma ótima resistência quando em contato com o elemento natural, ainda hoje o concreto é utilizado em obras de mesma finalidade.

O cimento é o aglomerante hidráulico utilizado na mistura do concreto, o qual em contato com a água forma uma pasta cimentícea aderente (meio ligante) entre os agregados, conferindo ao produto resistência e durabilidade ao longo de sua vida útil. Comumente utiliza-se o cimento Portland, resultado da queima dos materiais calcários, argilosos ou silicosos, os quais na etapa final passam por um processo de refinamento originando sua forma comercial. Quanto mais fino o cimento, mais rápida sua reação em contato com a água.

Conforme Ribeiro et al. (2006), os agregados constituintes do concreto são classificados de acordo com o método de obtenção, sejam através da fragmentação das rochas por ação da natureza ou através da trituração mecânica. Esses agregados representam $70 \%$ do volume do concreto, aumentando a capacidade de resistência da superfície do concreto.

A Norma Técnica Brasileira NBR NM 248 - Agregados - Determinação da composição granulométrica (ABNT, 2003), determina o ensaio para estudo da composição granulométrica dos agregados do concreto, através do peneiramento do material por meio de peneiras em série, que são classificadas conforme a abertura nominal de suas malhas.

Ainda de acordo com Ribeiro et al. (2006), os agregados podem ser classificados como graúdos ou miúdos, tudo conforme o módulo de finura (MF) das partículas, que é a soma das porcentagens retidas acumuladas dos agregados, quando passam pelo processo de peneiramento. Os agregados graúdos contribuem para uma menor retração volumétrica da pasta de cimento e os miúdos contribuem para uma menor perda de umidade do material, tudo provocado pela reação química entre o cimento e o agregado. As formas e texturas das partículas também contribuem para o desempenho do concreto, além de influenciarem diretamente no custo do produto final, uma vez que a forma e textura do agregado exige um maior ou menor consumo dos outros materiais, como água e cimento.

\subsection{Estados e durabilidade do concreto}

O estado do concreto compreende duas fases: fresco e endurecido. O concreto em seu estado fresco é caracterizado pelo período que antecede o início do enrijecimento do material (início de pega), é neste estado que o concreto ainda está em sua forma trabalhável, podendo assumir diversas formas. No estado endurecido, o concreto já se encontra em seu estado rígido (fim de pega), assumindo um estado impossível de trabalho, manuseio e lançamento.

A NBR 16889 (ABNT, 2020), determina o teste do abatimento do tronco de cone (slump test), para verificação da consistência do concreto, essa consistência pode ser classificada de seca a fluida e diz muito sobre as características das peças a serem concretadas. 
Segundo Neville (2016), a cura do concreto ainda na fase de enrijecimento do concreto é de suma importância, o seu grau de saturação deve estar em torno de $80 \%$ para evitar o surgimento de trincas e fissuras devido a retração da pasta cimentícia. Ainda, a cura do concreto é essencial quando se trata da sua durabilidade.

Outros mecanismos que podem afetar a durabilidade das estruturas de concreto como a lixiviação, expansão por sulfato e a reação álcali-agregado; esses mecanismos são acionados devido às condições nas quais os elementos estão expostos. Com isso a NBR 6118 (ABNT, 2014), estabelece a classe de agressividade do meio ambiente (CAA) na qual as estruturas se encontram.

\subsection{Ensaio de resistência à compressão axial do concreto}

De acordo com Mehta e Monteiro (1994) a característica mais importante do concreto é a sua resistência à compressão axial, ou seja, a sua capacidade de resistir a cargas de compressão axial. A NBR 8953 (ABNT, 2015a) estabelece as classes de resistência à compressão axial do concretos estruturais de acordo com a sua utilização.

Para o ensaio de compressão axial do concreto, amostras são coletadas das betonas e corpos de prova cilíndricos são moldados. Os moldes são preenchidos em camadas e adensados conforme método de adensamento utilizado, as dimensões dos moldes e seu formato, todos os procedimentos de moldagem são pré-estabelecidos pela NBR 5738 (ABNT, 2016).

A NBR 5739 (ABNT, 2018) estabelece os parâmetros de ensaio de resistência à compressão axial, onde os corpos de prova são rompidos em uma determinada idade. Para tal ensaio, uma prensa mecânica é utilizada como equipamento de aplicação da carga. $O$ carregamento aplicado deve ser contínuo, com uma velocidade de $(0,45 \pm 0,15) \mathrm{MPa} / \mathrm{s}$.

\subsection{Resistência característica à compressão axial}

De acordo com a NBR 12655 (ABNT, 2015b), quando se faz a amostragem total (amostragem de 100\% das betonadas produzidas), o maior valor obtido entre os corpos de prova (CPs), de uma mesma idade, é assumido como a resistência característica à compressão axial do exemplar em estudo, conforme Equação 1.

Onde:

$$
f_{c k, e s t}=f_{c, \text { betonada }}
$$

$f_{c k, e s t}$ : é o valor da resistência característica à compressão do exemplar da betonada, em MPa.

A NBR 5739 (ABNT, 2018) estabelece a Equação 2, para cálculo da resistência à compressão axial do concreto.

Onde:

$$
f_{c}=\frac{4 F}{\pi x D^{2}}
$$

$f_{c}$ : é a resistência à compressão axial do concreto, em $\mathrm{MPa}$;

$F$ : é a força máxima alcançada, em $\mathrm{N}$;

$D$ : é o diâmetro do corpo de prova, em $\mathrm{mm}$.

Para a norma de projetos de estrutura de concreto NBR 6118 (ABNT, 2014), a resistência característica à compressão do concreto pode ser estimada com o uso da Equação 3 (quando a verificação for em idade igual ou superior a 28 dias), e das Equações 4 e 5 (quando a verificação for em idade inferior a 28 dias).

Onde:

$$
f_{c k j}=f_{c k 28}=f_{c k}
$$

$f_{c k j}$ : é a resistência característica à compressão do concreto aos j dias, em MPa;

$f_{c k 28}$ : é a resistência característica à compressão do concreto aos 28 dias, em MPa; 
$f_{c k}$ : é a resistência característica à compressão do concreto, em MPa.

$$
f_{c k j}=\beta_{1} x f_{c k}
$$

Onde:

$$
\beta_{1}=\exp \left\{s\left(\left(1-\frac{28}{t}\right)^{\frac{1}{2}}\right)\right\}
$$

Onde:

$t$ : é a idade efetiva do concreto, em dias;

$s$ : é uma constante determinada pelo tipl de cimento ( $s=0,20$ para CP V-ARI).

\subsection{Resistência média de dosagem}

A resistência média de dosagem do concreto é estabelecida pela NBR 12655 (ABNT, 2015b), com o intuito de estimar a resistência média do concreto em função da resistência característica à compressão requerida em fase de projeto (Equação 6).

Onde:

$$
f_{c m}=f_{c k j}+1,65 x s_{d}
$$

$f_{c m}$ : é a resistência de dosagem aos j dias, em MPa;

$f_{c k j}$ : é a resistência característica do concreto aos j dias, em MPa;

$s_{d}$ : é o desvio padrão de dosagem, em MPa.

Este desvio padrão $s_{d}$ é estabelecido ainda pela NBR 12655 (ABNT, 2015b), conforme Quadro 1.

Quadro 1 - Desvio padrão $s_{d}$ conforme condições de preparo do concreto

\begin{tabular}{|c|c|l|}
\hline Classe & $\begin{array}{c}\text { Desvio Padrão } \\
\text { (Mpa) }\end{array}$ & \multicolumn{1}{c|}{ Características de preparo } \\
\hline A & 4,0 & $\begin{array}{l}\text { Cimento e agregados medidos em massa e a água de } \\
\text { amassamento medida em massa ou volume, a partir } \\
\text { de dispositivo dosador e corrigida em função da } \\
\text { umidade dos agregados }\end{array}$ \\
\hline B & 5,5 & $\begin{array}{l}\text { Cimento medido em massa, água medida em volume } \\
\text { por dispositivo dosador e os agregados medidos em } \\
\text { massa combinada com volume }\end{array}$ \\
\hline C & 7,0 & $\begin{array}{l}\text { Cimento medido em massa, agregados medidos em } \\
\text { volume e a água de amassamento medida em volume } \\
\text { e sua quantidade é corrigida em função da estimativa } \\
\text { da umidade dos agregados e da consistência do } \\
\text { concreto }\end{array}$ \\
\hline
\end{tabular}

Fonte: Autor (Adaptada de ABNT, 2015)

\section{Materiais e Métodos}

Para parte experimental foram utilizados agregados graúdos de origem calcária: brita $1(12,5 \mathrm{~mm})$ e brita 2 $(25 \mathrm{~mm})$, agregado miúdo de origem gnaize (areia de rio com MF de 2,59 mm), cimento CP V-ARI (cimento 
Portland de alta resistência inicial) e água livre de impurezas. Adotou-se, em proporção dos agregados graúdos na mistura, $60 \%$ de brita 2 e $40 \%$ de brita 1 .

A relação a/c adotada foi de 0,52 , com base nos critérios de agressividade II, estabelecido pela NBR 6118 (ABNT, 2014), o Quadro 2 apresenta o traço unitário e em massa obtido.

Quadro 2 - Traços unitário e em massa, obtido pelo método da ABCP (Elaborado pelos autores)

\begin{tabular}{|c|c|c|c|c|c|}
\hline Traço & Cimento & Brita 2 & Brita 1 & Areia natural & Água \\
\hline Unitário & 1 & 1,65 & 1,10 & 1,82 & 0,52 \\
\hline Massa $(\mathrm{kg})$ & 13,70 & 22,55 & 15,04 & 24,94 & 7,17 \\
\hline
\end{tabular}

$\mathrm{O}$ abatimento do troco de cone requerido de $(8,0 \pm 2,0) \mathrm{cm}$ foi requerido com um slump de $10 \mathrm{~cm}$, como mostra a Figura 1.

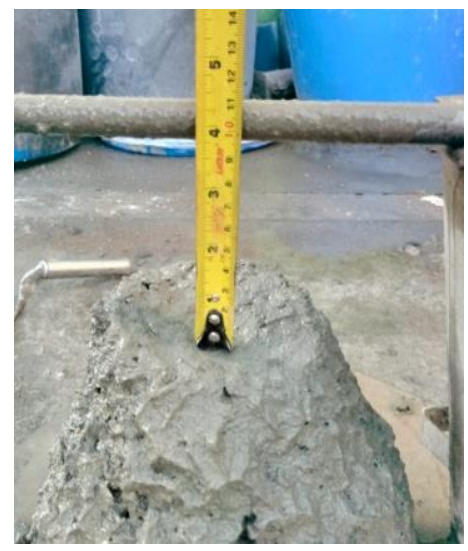

Figura 1 - Slump test (Acervo dos autores, 2020)

Foram moldados sete exemplares, com 2 corpos de prova cada (Figura 2). Os corpos de prova foram colocados em câmara úmida após 24 horas dentro dos moldes até o dia de análise pré estabelecido, a cura foi feita em um tanque com água livre de impurezas e com cal (Figura 3).

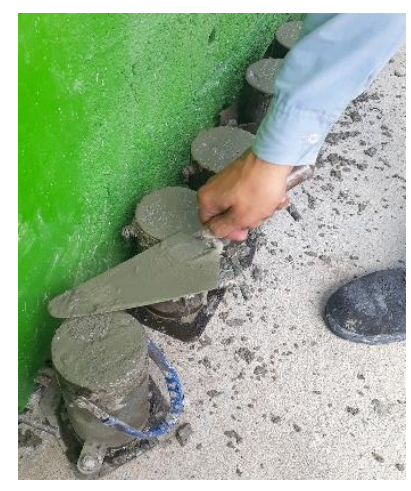

Figura 2 - Moldagem (Acervo dos autores, 2020)

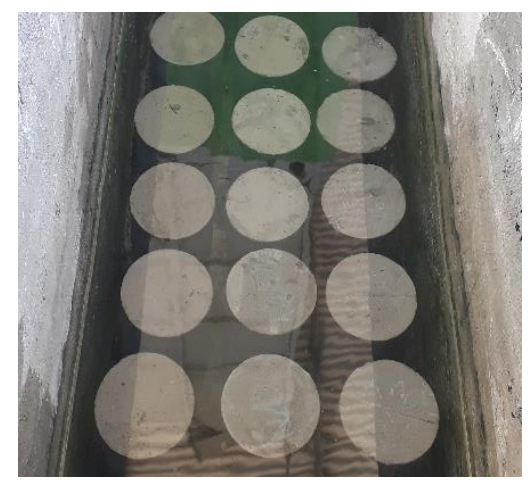

Figura 3 - Tanque de cura (Acervo dos autores, 2020)

Os rompimentos dos corpos de prova foram realizados através de uma prensa mecânica, com idades de 24 horas, 3 dias, 5 dias, 7 dias, 14 dias, 21 dias e 28 dias. 0 maior valor dentre os dois corpos de prova de cada exemplar, irá caracterizá-lo como a resistência característica à compressão do concreto para aquela idade.

A estimativa da NBR 6118 (ABNT, 2014) para os valores de $f_{c k j}$ serão obtidas por meio da aplicação das equações presentes no Item 1.4 e, são baseados na resistência característica a compressão obtida em ensaio na idade de 28 dias (41,6 MPa). 


\section{Resultados}

Após a execução dos ensaios de resistência à compressão axial do concreto dos 7 exemplares, foram obtidos os resultados que se encontram no Quadro 3, os valores em negrito representam a resistência característica à compressão axial do exemplar.

Quadro 3 - Resistência à compressão axial do concreto conforme experimento (Elaborado pelos autores)

\begin{tabular}{|c|c|c|c|c|c|}
\hline Idade & \multicolumn{2}{|c|}{$\begin{array}{c}\mathbf{f}_{c k}-\text { Experimental } \\
\text { (MPa) }\end{array}$} & Idade & \multicolumn{2}{c|}{$\begin{array}{c}\text { fckj - Experimental } \\
\text { (MPa) }\end{array}$} \\
\hline 24 horas & $\mathbf{1 1 , 2 5}$ & 10,77 & 14 dias & 32,96 & $\mathbf{3 3 , 1 5}$ \\
\hline 3 dias & 21,04 & $\mathbf{2 4 , 3 6}$ & 21 dias & 33,87 & $\mathbf{3 5 , 9 3}$ \\
\hline 5 dias & $\mathbf{2 8 , 5 7}$ & 28,55 & 28 dias & 39,00 & $\mathbf{4 1 , 7 0}$ \\
\hline 7 dias & 31,32 & $\mathbf{3 1 , 6 0}$ & \multicolumn{4}{|l}{} \\
\hline
\end{tabular}

A variação considerável no resultado entre os dois corpos de prova de alguns exemplares (como o de 3 dias e 21 dias) pode ter ocorrido devido algumas falhas de execução que possam ter apresentado no processo, como velocidade de rompimento heterogênea, adensamento manual não homogêneo durante a moldagem dos corpos de prova. De acordo com um estudo proposto por Mascolo (2012), as altas variações os resultados podem surgir de falhas durante as várias operações de ensaio ou a ocorrência de concentração de carga não uniforme devido as irregularidades das bases dos corpos de prova, isso foi observado durante o seu estudo.

O Quadro 4 apresenta os resultados estimados de resistência à compressão axial do concreto para as diversas idades do estudo levando em conta os critérios da NBR 6118 (ABNT, 2014) e a resistência característica do concreto de 41,7 Mpa, encontrada no experimento (aos 28 dias).

Quadro 4 - Resistência característica à compressão axial do concreto estimada pela NBR 6118 (ABNT, 2014) (Elaborado pelos autores)

\begin{tabular}{|c|c|c|c|}
\hline Idade & $\begin{array}{c}f_{c k j}-\text { NBR } 6118 \\
\text { (MPa) }\end{array}$ & Idade & $\begin{array}{c}f_{c k j}-\text { NBR } 6118 \\
\text { (MPa) }\end{array}$ \\
\hline 24 horas & 17,68 & 14 dias & 38,38 \\
\hline 3 dias & 27,65 & 21 dias & 40,43 \\
\hline 5 dias & 31,73 & 28 dias & 41,70 \\
\hline 7 dias & 34,14 & & \\
\hline
\end{tabular}

Com base na comparação dos resultados obtidos experimentalmente (Quadro 3) com os valores estimados propostos pela aplicação da metodologia da NBR 6118 (ABNT, 2014), mostrados no Quadro 4, vê-se um caráter não conservador da norma de projetos com relação às resistências características à compressão em idades inferiores a 28 dias.

Esperava-se que a norma de projeto fosse completamente conservadora, uma vez que ela tem o intuito de delinear cálculos estruturais que estabelecem a resistência de cálculo à compressão axial para um material em que seu comportamento mecânico depende de inúmeros fatores. Porém o estudo foi conduzido com um número reduzido de corpos de prova por idade e com traço e materiais específicos, ressaltando que o não conservadorismo não deve ser aplicado de forma generalizada.

Para a melhor visualização dos dados obtidos (estimativa normativa e dados experimentais), foi elaborado um gráfico onde se pode verificar visualmente, o comportamento da curva em crescimento e a dispersão entre valores obtidos (Gráfico 1). Nos valores apresentados constam uma variação máxima entre dois corpos de prova de mesmo exemplar de 15,78\% (3 dias) e uma variação mínima de 0,07\% (5 dias). 
Gráfico 1 - Análise gráfica das resistências de compressão axial (Elaborado pelos autores)

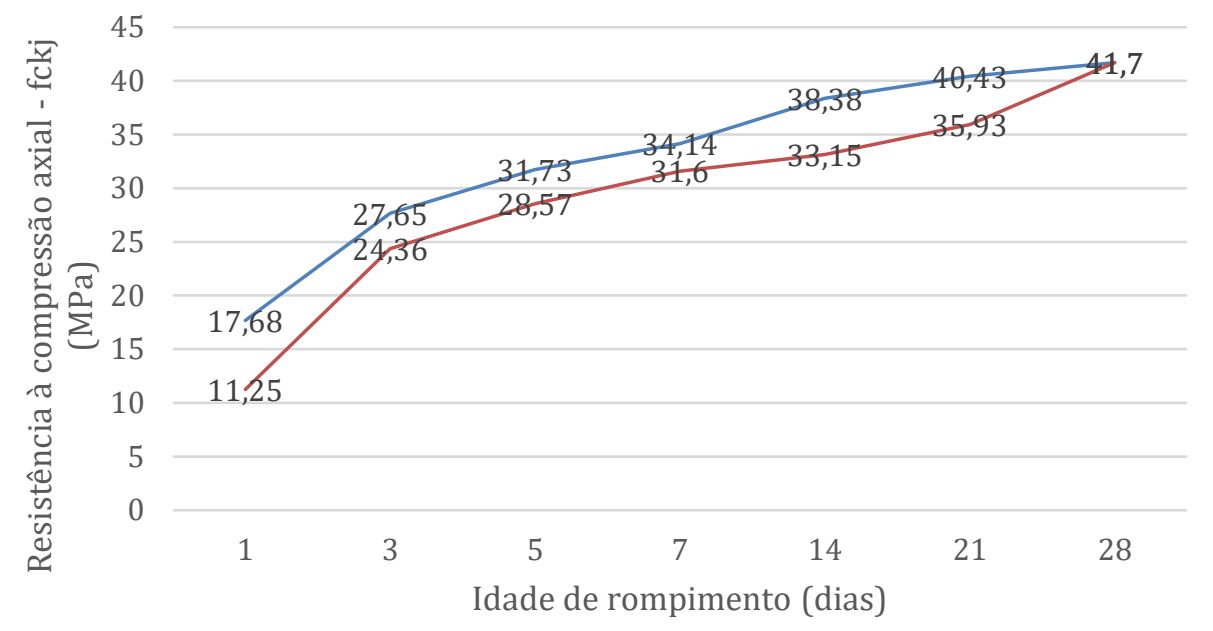

— NBR 6118 Resistência Experimental

\section{Conclusões}

Apesar da dispersão entre os resultados experimentais e os estabelecidos pela NBR 6118 (ABNT, 2014), é perceptível pela análise gráfica que ambas as curvas apresentaram similaridade quanto à velocidade de crescimento.

Para uma conformidade entre os resultados dos exemplares, percebeu-se a dependência da excelência em todos os processos de execução do ensaio, além de uma análise apurada dos materiais constituintes da mistura.

Apesar da norma de projetos NBR 6118 (ABNT, 2014) não se apresentar conservadora por completo, podese considerá-la em partes, baseando no resultado da resistência aos 28 dias, idade importante a qual serve como parâmetro de aceitação do concreto. Cabe ressaltar que o estudo realizado foi específico para uma composição de concreto e restrito as idades analisadas e que, para uma conclusão definitiva acerca do viés conservador ou não da NBR 6118 (ABNT, 2014), são necessários inúmeros estudos com variação da composição do concreto e números de corpos de prova adotados.

\section{Agradecimentos}

Agradecemos ao Centro Federal de Educação Tecnológica de Minas Gerais - CEFET-MG pelo apoio direto e indireto a este trabalho e a empresa City Mix Concreto pela doação dos materiais utilizados e por ter cedido o espaço físico (equipamento e laboratório) para a realização do experimento. Agradecemos também ao LAR - Laboratório de Avaliação e Reabilitação de Ambiente Construído CEFET-MG - Campus Curvelo, pelo apoio durante o desenvolvimento do estudo.

\section{Referências Bibliográficas}

ASSOCIAÇÃO BRASILEIRA DE NORMAS TÉCNICAS. NBR 16889: Concreto - Determinação da consistência de abatimento do tronco de cone. Rio de Janeiro, 2020. . NBR 5739: Concreto - Ensaio de compressão de corpos de prova cilíndricos. Rio de Janeiro, 2018. . NBR 5738: Concreto - Procedimento para moldagem e cura de corpos de prova. Rio de Janeiro, 2016. . NBR 8953: Concreto para fins estruturais. Rio de Janeiro, 2015a.

- NBR 12655: Concreto de cimento Portland - Preparo, controle, recebimento e aceitação Procedimentos. Rio de Janeiro, 2015b.

. NBR 6118: Projetos de estruturas de concreto - Procedimentos. Rio de Janeiro, 2014. 
. NBR NM 284: Agregados - Determinação da composição granulométrica. Rio de Janeiro, 2003.

Boggio, A.J. (2000). Estudo Comparativo de Métodos de Dosagem de Concreto de Cimento Portland. Dissertação de Mestrado. Universidade Federal do Rio Grande do Sul, Porto Alegre.

Mehta, P.K., Monteiro, P.J.M. (1994). Concreto: Estruturas, Propriedade e Materiais. São Paulo: Pini, 1994, Ed.1.

Moscolo, R. (2012). Concreto Usinado: Análise da Variação da Resistência à Compressão e de Propriedades Físicas ao Longo da Descarga do Caminhão Betoneira. Dissertação de Mestrado. Universidade Federal do Rio Grande do Sul, Porto Alegre.

Ribeiro, C.C., Pinto, J.D.S., Starling, T. (2006). Materiais de Construção Civil. Belo Horizonte: UFMG, 2006, Vol.2. 